\title{
The impact of COVID-19 related 'stay-at-home' restrictions on food prices in Europe: findings from a preliminary analysis
}

\author{
Sonia Akter ${ }^{1}$ (iD \\ Received: 28 April 2020 / Accepted: 30 June 2020 / Published online: 8 July 2020 \\ (C) International Society for Plant Pathology and Springer Nature B.V. 2020
}

\begin{abstract}
This study examines the impact of COVID-19 related 'stay-at-home' restrictions on food prices in 31 European countries. I combine the European Union's Harmonised Index of Consumer Prices (HICP) with the Stay-at-Home Restriction Index (SHRI) from the Oxford COVID-19 Government Response Tracker (OxCGRT) dataset for January-May 2020. The results of a series of difference-in-difference regression models reveal that the severity of stay-at-home restrictions increased overall food prices by $1 \%$ in March 2020, compared to January and February 2020. The price level for food continued to rise in the high stay-at-home restriction countries relative to thier counterpart in April but stabilised in May. The food categories that witnessed the most significant surges in prices were meat, fish \& seafood, and vegetables. The prices of bread \& cereals, fruits, milk, cheese \& eggs and oils \& fats were not significantly affected. The correlations between food prices and stay-at-home restrictions were significant after controlling for cross-country variations in COVID-19 affectedness and other mitigation and adaptation measures, such as international travel controls, road closures and the size of the economic stimulus packages. This study presents the first empirical evidence of food price inflation as an unintended consequence of COVID-19 pandemic containment measures in one of the most severely hit continents of the world.
\end{abstract}

Keywords Coronavirus $2($ SARS-CoV-2) $\cdot$ Pandemic $\cdot$ Social distancing $\cdot$ Lockdown $\cdot$ Food security

\section{Introduction}

European countries are among the worst-hit by the COVID-19 pandemic, which has claimed approximately half a million lives globally (as of 24 June 2020) (ECDC 2020). Over one-third of the current COVID-19 fatalities have occurred in Europe, most notably in the United Kingdom, Spain, Italy, Germany and France (ECDC 2020). The rapid surge in the number of COVID-19 infections and deaths prompted governments to introduce prevention and mitigation measures in a desperate effort to contain the spread of the virus.

Electronic supplementary material The online version of this article (https://doi.org/10.1007/s12571-020-01082-3) contains supplementary material, which is available to authorized users.

Sonia Akter

sonia.akter@nus.edu.sg

1 Lee Kuan Yew School of Public Policy, National University of Singapore, 469C Bukit Timah Road, Singapore 259772, Singapore
A 'stay-at-home' requirement or lockdown, an unprecedented measure that limits population movement within a country, has been adopted by many European leaders as a dominant strategy to curb the rising tide of infections caused by the deadly virus. Such restrictions are expected to have detrimental effects on food demand and supply. On the one hand, they disrupt the food supply chain by causing worker shortages and hindering the flow of goods and services (Cappelli and Cini 2020; Cullen 2020). On the other hand, consumers engage in panic buying, which leads to empty shelves in grocery stores (Power et al. 2020; Bhattacharjee and Jahanshah 2020). The combined effect of supply disruption and demand surge is short-term food price inflation. While the theoretical implications of broad movement restrictions on food prices are widely accepted, empirical evidence of this phenomenon is currently non-existent in the literature.

In this study, I present the first empirical evidence of the impact of stay-at-home restrictions enforced during the COVID-19 crisis on food prices from a preliminary assessment that uses data from the European Union's (EU) Harmonised Index of Consumer Prices (HICP) and the Oxford COVID-19 Government Response Tracker 
(OxCGRT) for January to May 2020 (Eurostat 2020; Hale et al. 2020a). The sample includes 25 EU countries and the United Kingdom, Norway, Iceland, Switzerland, Siberia and Turkey (henceforth called EU +6). ${ }^{1}$

I focus on stay-at-home restrictions rather than international movement restrictions because all EU countries implemented border closures that limit cross-country variation along this policy dimension (European Commission 2020a). While all of the sampled countries eventually introduced the stay-at-home restriction, there was variation concerning their stringency (advice versus mandatory), coverage (targeted versus general) and duration (number of days the restriction was in place). Particularly during the earlier phase of the pandemic, countries responded differently and at different speeds, as reports of COVID-19 infections and deaths started to surface in their own and neighbouring countries. Most countries first introduced social distancing measures to varying degrees. As the number of reported infections and deaths surged, some countries (e.g. Italy, Germany) progressively tightened their social distancing measures to full or partial lockdown (i.e. a mandatory stay-at-home order). Other countries (e.g. Sweden, Iceland) advised citizens to work from home and avoid large gatherings, but no mandatory stay-at-home order was issued. The speed at which countries acted also varied. Italy introduced a nationwide lockdown on 9 March 2020 - 38 days after their first reported COVID-19 infection and 463 reported COVID-19 deaths (Deutsche Welle 2020; ECDC 2020). Germany introduced a lockdown on 22 March 2020 - 54 days after their first reported COVID-19 infection and 94 reported COVID-19 deaths (Deutsche Welle 2020; ECDC 2020).

The wide variation in how the stay-at-home restriction was introduced and enforced offers a unique opportunity to study this measure's impact on food prices. Using the Stay-at-Home Restriction Index (SHRI) of the OxCGRT, I divide the sampled countries into high and low restriction groups. The SHRI captures three aspects of a stay-at-home restriction: (1) stringency, (2) coverage and (3) duration. Combining the SHRI with the HICP for food, I estimate a series of difference-indifference panel regression models to compare price changes before and after the implementation of these restrictions, and between countries with relatively higher versus lower levels of restrictions. The findings reveal a significant positive correlation between the SHRI and food price indices in March relative to January and February. More specifically, countries that faced stricter stay-at-home restrictions witnessed approximately $1 \%$ price inflation for all food items in March compared with those that faced less strict restrictions.

\footnotetext{
${ }^{1}$ Countries were selected based on the HICP and OxCGRT data availability. OxCGRT data was missing for Malta and North Macedonia. While Turkey is not a European country, HICP data was available, which is probably due to the EU-Turkey Customs Union agreement that makes Turkey an important trading partner of the EU (European Commission 2020b).
}

Of the seven food categories examined, the price indices for meat, fish \& seafood, and vegetables were most affected. The indices for bread \& cereals, fruits, milk, cheese \& eggs, and oil $\&$ fats responded little to reduced population movement.

The positive correlations between the SHRI and food price indices in March persisted, even after accounting for crosscountry heterogeneity in pandemic affectedness and other mitigation and adaptation measures. Pandemic affectedness was measured using the number of COVID-19 infections and deaths per thousand people. Internal and international travel controls were measured using OxCGRT's internal and international travel controls indices. Finally, economic responses were measured using the size of the per capita economic stimulus package. As these control variables did not overshadow the positive association between the SHRI and food price indices, it ruled out many alternative explanations for the observed food price inflation in the high restriction countries relative to their counterparts.

Section 2 describes the data followed by an outline of the empirical strategy in Section 3. Section 4 presents descriptive statistics, and Section 5 presents the results. Section 6 summarises the results and offers concluding remarks.

\section{Data}

\subsection{Food price indices}

The HICP uses a specific CPI basket of items and is calculated following a standardised approach for the EU member countries and a handful of non-EU countries that are part of the European Economic Area (Eurostat 2020). The indices are prepared by the national statistical institutes in each of the partner countries. The Eurostat curates and documents these statistics. I use the following eight indices from the HICP: (1) food, (2) bread \& cereals, (3) meat, (4) fish \& seafood, (5) vegetables, (6) fruits, (7) milk, cheese \& eggs, and (8) oils \& fats.

\subsection{Stay-at-home restriction index (SHRI)}

The OxCGRT tracks governmental COVID-19 responses in real-time and aggregates them in 18 policy domains (Hale et al. 2020b). The stay-at-home restriction is one of the 18 indicators. The stringency of the stay-at-home requirement is measured on a scale of 0 to $3(0=$ no measures, $1=$ recommend not leaving house, $2=$ require not leaving house with exceptions for exercise, grocery shopping, and 'essential' trips, 3 = require not leaving house with minimal exceptions). The coverage of these indicators is measured on a binary scale $(0=$ targeted, $1=$ general $)$. The SHRI is calculated by adding the two sub-indices, before multiplying them by the number of days the restrictions had been in place and averaging them over a month. More specifically: 
$\operatorname{SHRI}_{i t}=\frac{\left(S_{i t}+C_{i t}\right) * d_{i t}}{n_{t}}$

where $t$ is month, $i$ is country, $S_{t}$ is stringency score, $C_{t}$ is geographical coverage score, $d_{t}$ is number of days a measure had been in place, and $n$ is number of days in a month. The SHRI ranges from 0 to 4 . Note that the SHRI only includes requirements pertaining to home confinement. It does not measure other forms of restrictions, such as school closures, workplace closures, or the cancellation of events and public transport. The OxCGRT uses separate indices to capture those measures.

\subsection{Control variables}

I use three additional OxCGRT indices to control for timevarying heterogeneities across countries: international travel controls, internal movement restriction (i.e. road closure) and fiscal stimulus. The international travel controls index involves four values: $0=$ no measures, $1=$ screening, $2=$ quarantine for highrisk regions, $3=$ ban for high-risk regions. The internal movement restriction index has three values: $0=$ no measures, $1=$ recommend closing or significantly reducing volume/route/ means of transport, 2 = require closing or prohibiting most people from using it. The fiscal stimulus variable is the per capita value of the economic stimulus packages in US dollars, including government spending and tax cuts.

Indicators of pandemic affectedness are included as control variables, and measured using the number of reported COVID-19 infections and deaths per 1000 people. The data for these two variables were taken from the European Centre for Disease Control website (ECDC 2020).

\section{Empirical strategy}

A difference-in-difference regression specification was used to examine the impact of movement restrictions on food price indices. More specifically:

$$
\begin{aligned}
\text {HICP }_{i t}= & \beta_{0}+\beta_{1} \text { SHRID }_{i}+\beta_{2} \text { Post }_{t} \\
& +\beta_{3} \text { SHRID }_{i} * \text { Post }_{t}+\beta_{4} X_{i t}+\varepsilon_{i t}
\end{aligned}
$$

where $i$ is country, $t$ is month, $H_{C C P}$ it the food price index for a particular food category, $S H R I D_{i}$ is a dummy variable which takes a value of 1 or 0 if the SHRI value is greater than or less than 1.19 (mean value in March 2020), respectively, and Post is a dummy variable for months ( 0 for January and February and 1 otherwise). I use the SHRI value for March 2020 to assign countries to high and low restriction groups because all countries gradually tightened their stayat-home restrictions in April and May 2020, which reduced variation in the SHRI score across countries. The largest variation in the SHRI score among countries persisted in March 2020. Countries that scored high on the SHRI in March continued to score high in April and May because the duration of the restriction being in place was higher in high restriction countries than their low restriction counterparts.

$X_{i t}$ is a vector of five control variables: the index of international and internal movement restrictions, fiscal stimulus and the number of COVID-19 infections and deaths per 1000 people.

Due to the panel structure of the data, $\beta_{1}$ drops out of the model because country-specific unobserved characteristics that are time-invariant (e.g. institutional efficacy, government's competency, level of corruption) are cancelled out in a panel data regression. $\beta_{2}$ captures the time trend of food prices, being how much the price level would have changed without COVID-19 related disruptions. $\beta_{3}$ is the coefficient of interest, which estimates the change in HICP in postrestriction months compared to the average price level of the pre-restriction months (i.e. January and February) and between countries with relatively higher versus lower levels of stay-at-home restrictions.

\section{Descriptive statistics and food price trends}

Table 1 presents descriptive statistics for the sampled countries for January, February and March 2020. The list of countries that were categorised as high and low restriction groups is in Supplementary Material (SM) 1.

Figure 1 presents the trend in aggregate HICP for all food items between January 2019 and May 2020 for high and low restriction groups. Similar figures are presented in SM 2-7 for the seven individual food categories. The HICP for these two groups followed almost parallel trajectories until February 2020. Between January and February 2020, the HICP of both groups rose by approximately 1 point. Between February and March 2020, the HICP declined by 0.19 points in the low restriction group but rose by 0.81 points in the high restriction group. This indicates that the high restriction group had an approximate $1 \%$ increase in overall food prices in March, relative to the low restriction group.

In the high restriction group, the HICP increased by 1.56 points between March and April. The low restriction group also witnessed price inflation of 0.53 points during the same period. This implies that food prices increased by another 1 point in the high restriction group in April. The HCIP rose by 1.10 points between April and May in the low restriction group while it rose by 0.27 points in the high restriction group. This implies that food prices in the high restriction group countries started to stabilise in May, but started to surge in the low restriction group countries. The reason for the rise in the HICP for the low restriction group, as mentioned before, is most likely due to an increase in the SHRI as well as other response measures introduced to contain the COVID-19 outbreak. 
Table 1 Summary statistics

\begin{tabular}{|c|c|c|c|c|c|c|c|c|c|c|c|c|c|c|c|}
\hline \multirow[t]{2}{*}{ Variables } & \multicolumn{5}{|c|}{ January 2020} & \multicolumn{5}{|c|}{ February 2020} & \multicolumn{5}{|c|}{ March 2020} \\
\hline & $\mathrm{N}$ & Mean & SD & Min & Max & $\mathrm{N}$ & Mean & SD & Min & Max & $\mathrm{N}$ & Mean & SD & Min & Max \\
\hline HICP Food & 31 & 110.56 & 13.86 & 93.40 & 179.40 & 31 & 111.41 & 14.63 & 93.10 & 183.84 & 31 & 111.81 & 15.28 & 93.10 & 187.46 \\
\hline HICP Bread \& Cereals & 31 & 108.14 & 14.11 & 91.60 & 177.76 & 31 & 108.53 & 14.48 & 91.60 & 179.85 & 31 & 109.00 & 14.63 & 92.00 & 181.19 \\
\hline HICP Meat & 31 & 110.29 & 11.54 & 93.00 & 160.53 & 31 & 111.07 & 12.10 & 93.30 & 164.38 & 31 & 111.96 & 13.55 & 93.20 & 172.49 \\
\hline HICP Fish \& Seafood & 31 & 114.24 & 13.53 & 95.50 & 175.65 & 31 & 114.26 & 14.36 & 93.20 & 180.04 & 31 & 115.01 & 15.02 & 93.80 & 184.57 \\
\hline HICP Vegetables & 31 & 119.10 & 22.12 & 95.60 & 211.93 & 31 & 121.82 & 24.07 & 95.00 & 220.53 & 31 & 120.08 & 25.06 & 94.50 & 225.26 \\
\hline HICP Fruits & 31 & 110.61 & 12.15 & 96.10 & 161.95 & 31 & 112.22 & 14.31 & 97.90 & 173.28 & 31 & 113.72 & 15.16 & 98.00 & 180.31 \\
\hline HICP Milk, Cheese \& Eggs & 31 & 108.63 & 16.41 & 93.90 & 191.61 & 31 & 109.23 & 16.57 & 94.10 & 192.64 & 30 & 109.67 & 16.23 & 94.10 & 189.74 \\
\hline HICP Oils \& Fats & 31 & 112.59 & 14.76 & 92.87 & 179.64 & 31 & 112.96 & 15.57 & 92.03 & 181.83 & 31 & 113.91 & 15.69 & 91.88 & 183.33 \\
\hline SHRI & 31 & 0 & 0 & 0 & 0 & 31 & 0.02 & 0.09 & 0 & 0.48 & 31 & 1.18 & 0.69 & 0 & 3.10 \\
\hline SHRID & 31 & 0 & 0 & 0 & 0 & 31 & 0 & 0 & 0 & 31 & 0.55 & 0.51 & 0 & 1 & 31 \\
\hline Internal movement restriction index & 31 & 0 & 0 & 0 & 0 & 31 & 0.02 & 0.11 & 0 & 0.62 & 31 & 1.08 & 0.52 & 0 & 2.71 \\
\hline International travel controls index & 31 & 0.06 & 0.13 & 0 & 0.42 & 31 & 0.65 & 1.05 & 0 & 3 & 31 & 2.19 & 0.92 & 0 & 3.52 \\
\hline $\begin{array}{l}\text { Fiscal stimulus per capita (million } \\
\text { US\$) }\end{array}$ & 31 & 0 & 0 & 0 & 0 & 31 & 0 & 0 & 0 & 0 & 31 & 0.01 & 0.03 & 0 & 0.16 \\
\hline $\begin{array}{l}\text { Number of COVID-19 deaths per } \\
1000 \text { people }\end{array}$ & 31 & 0 & 0 & 0 & 0 & 31 & 0 & 0 & 0 & 0 & 31 & 0.03 & 0.07 & 0 & 0.36 \\
\hline $\begin{array}{l}\text { Number of COVID-19 cases per } 1000 \\
\text { people }\end{array}$ & 31 & 0 & 0 & 0 & 0 & 31 & 0.001 & 0.003 & 0 & 0.015 & 31 & 1.65 & 5.73 & 0.05 & 32.29 \\
\hline
\end{tabular}

\section{Results}

\subsection{Price inflation for all food items}

Table 2 presents panel fixed effects ${ }^{2}$ regression models for all food items using Eq. 2. Columns 1, 2 and 3 present findings using January and February as pre-restriction months and March as the post-restriction month. This setup allows clearer identification for the high and low restriction groups compared to a setup that includes April and May in the postrestriction period. Two auxiliary regression models are presented in Columns 4 and 5 to examine how food price trajectories changed in these two groups of countries during April and May.

Column 1 presents coefficients estimated from a model with no control variables. Column 2 presents coefficients estimated from a model with the full set of control variables. Column 3 presents coefficients estimated from a model excluding an outlier ${ }^{3}$ value. The coefficients of SHRIDxPost estimate the average difference in the HCIP between high and low restriction groups before and after the restrictions came into force. Across the first three models, the coefficients

\footnotetext{
${ }^{2}$ The Hausman test confirms that the null hypothesis (i.e. both random effects and fixed effects estimators are consistent) could not be rejected $\left(\mathrm{Chi}^{2}=7.65\right.$; $p=0.265)$.

${ }^{3}$ Cyprus posted a large drop in the HICP for vegetables in March 2020 (122.47) relative to its February 2020 value (149.15). To rule out the possibility that this large drop in vegetables prices was driving the results, Cyprus was excluded from the analysis.
}

of SHRIDxPost are positive and significant at the $5 \%$ level. They range from 0.986 to 1.122 , indicating that the stay-athome restriction led to approximately $1 \%$ food price inflation in March relative to the average price level of January and February. The magnitudes of the SHRIDxPost coefficients are consistent with the estimates derived from the graphical analysis (Fig. 1).

Column 4 presents results from the full sample, and Column 5 presents results obtained using March as the baseline (excluding January and February). The coefficients of the SHRIDxPost presented in Column 4 reveal that the HICPs in March, April and May were on average significantly higher than the average HICP in January and February in the high restriction countries relative to the low restriction countries. The coefficients of the SHRIDxPost presented in Column 5 estimate the change in the HICP in April and May relative to March. These coefficients help us understand whether food prices continued to rise in high restriction countries. The coefficients suggest that the high restriction countries had significantly higher HICP in April, relative to March, but the change in HICP did not significantly differ between high and low restriction groups in May.

\subsection{Price inflation for specific food categories}

To understand which food groups experienced the greatest surges in prices, a series of seven difference-in-difference regression models were estimated using Eq. 2. Table 3 presents 
Fig. 1 Price trend of all food items in the sampled countries with low and high restrictions (January 2019-May 2020)

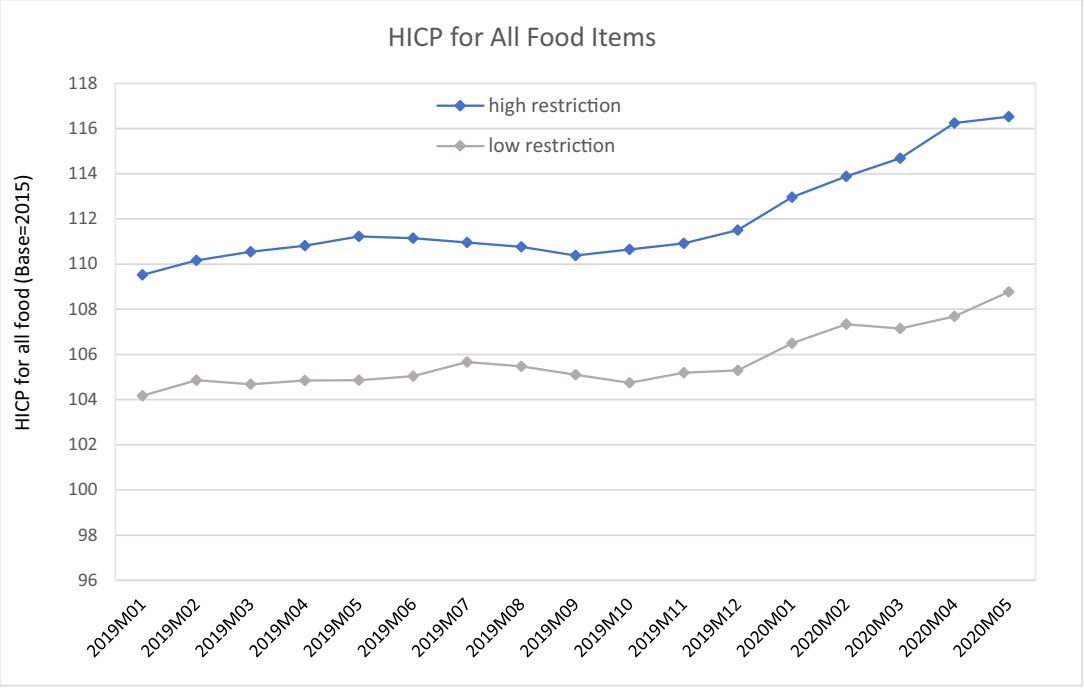

Source: Eurostat. (2020). the results for seven food groups. Results from only full models are presented. Columns 1, 5, 6 and 7 of Table 3 report the difference-in-difference regression coefficients
(SHRIDxPost) for the HICP of bread \& cereals, fruits, milk, cheese \& eggs and oil \& fats, respectively. Although positive, none of the estimated coefficients is significant at the $10 \%$

Table 2 Correlation between the HICP for all food items and the Stay-at-Home Requirement Index (panel fixed effects regression model)

HICP for all food items

(1) $\quad(2)$

SHRID ${ }^{\mathrm{a} x P o s t}$ (March)

$0.986 * *$

(2)

(3)

$1.122 * *$

..

SHRID $^{\mathrm{a} x \text { Post (April) }}$

SHRID ${ }^{a}$ xPost (May)

Post (February) ${ }^{\mathrm{b}}$

Post (March) ${ }^{\mathrm{b}}$

Post (April) ${ }^{\mathrm{b}}$

..

Post (May) ${ }^{\mathrm{b}}$

Control variables

Outlier value excluded ${ }^{\mathrm{c}}$

R-squared

Number of observations

Number of groups
(0.186)

$0.701 * *$

(0.260)

..

$0.840 * * *$

$0.849 * * *$

(0.181)

0.519

(0.362)

..

\begin{tabular}{lll}
$0.987 * *$ & $1.063 * *$ &.. \\
$(0.427)$ & $(0.453)$ & \\
.. & $2.055^{* *}$ & $0.824 * *$ \\
& $(0.828)$ & $(0.389)$ \\
.. & $1.698^{* *}$ & 0.689 \\
& $(0.688)$ & $(0.443)$ \\
$0.855^{* * *}$ & $0.828^{* * *}$ &.. \\
$(0.186)$ & $(0.206)$ & \\
$0.689 * *$ & $0.751 * *$ &.. \\
$(0.336)$ & $(0.276)$ & \\
.. & $1.507 * * *$ & $0.780 * *$ \\
& $(0.485)$ & $(0.299)$ \\
.. & $1.996 * * *$ & $1.256 * * *$ \\
& $(0.443)$ & $(0.308)$ \\
$\mathrm{Y}$ & $\mathrm{Y}$ & $\mathrm{Y}$ \\
$\mathrm{Y}$ & $\mathrm{N}$ & $\mathrm{N}$ \\
0.476 & 0.572 & 0.590 \\
90 & 154 & 92 \\
30 & 31 & 31 \\
\hline
\end{tabular}

The dependent variable is the HICP (base = 2015) for all food items. Robust standard errors in parenthesis

${ }^{\text {a }}$ SHRID stands for Stay-at-Home Restriction Index Dummy. SHRID $=1$ if SHRI $>1.19$ and SHRID $=0$ if SHRI $\leq 1.19$

${ }^{\mathrm{b}}$ Base month = January 2020

${ }^{\mathrm{c}}$ Cyprus is excluded from the sample due to the presence of an outlier value

$* * * p<0.01, * * p<0.05$

.. means not applicable 
level. This implies no significant increase in the price level of these categories of food in March, April and May compared to the average price level of the pre-restriction months (i.e. January and February) in high or low restriction countries.

Columns 2, 3 and 4 of Table 3 present the coefficients of SHRIDxPost for the HICP of meat, fish \& seafood and vegetables for the months of March, April and May. All coefficients are positive and significant at the five and $10 \%$ level for meat, fish \& seafood and vegetables (except for vegetables in May). The coefficient of SHRIDxPost for meat is 0.921 in March, 1.973 in April and 2.226 in May. This implies that although meat price in high restriction countries significantly increased in March and April relative to January and February, the price stabilised in May. The HICP for fish \& seafood in March was, on average, 1.407 points higher in the high restriction group than the low restriction group. The HICP for fish \& seafood continued to rise in April and May relative to their prior months. The HICP for vegetables in March and April differed by 3.363 and 4.484 points, respectively, in the high restriction group compared to the low restriction group. Note that this coefficient was obtained after excluding an outlier observation (i.e. Cyprus).

\section{Conclusions}

This study presents findings from a preliminary assessment of the impact of stay-at-home restrictions on food prices in Europe. Using monthly food price indices from 31 European countries for January-May 2020, I estimated a series of panel data fixed effects regression models using a difference-indifference specification. The results reveal a significant positive impact of relatively stringent stay-at-home restrictions on overall food prices. The most conservative estimate suggests a $0.987 \%$ increase in food prices due to a relatively stricter form of stay-at-home restrictions in March than in January and February.

Of the seven food categories examined, the HICPs for bread \& cereal, fruits, milk, cheese \& eggs and oils \& fats were unaffected by stay-at-home restrictions. In contrast, the HICPs for meat and fish \& seafood increased significantly in March in countries that were part of the high restriction group compared to countries that had relatively low or no stay-at-home restrictions in place. These results are consistent with the graphical analyses presented in the SMs. For vegetables, while the difference-in-difference

Table 3 Correlations between the HICP for seven food categories and the Stay-at-Home Requirement Index (panel fixed effects regression model)

\begin{tabular}{|c|c|c|c|c|c|c|c|}
\hline & $\begin{array}{l}\text { Bread \& cereals } \\
\text { (1) }\end{array}$ & $\begin{array}{l}\text { Meat } \\
\text { (2) }\end{array}$ & $\begin{array}{l}\text { Fish \& seafood } \\
\text { (3) }\end{array}$ & $\begin{array}{l}\text { Vegetables } \\
\text { (4) }\end{array}$ & $\begin{array}{l}\text { Fruits } \\
\text { (5) }\end{array}$ & $\begin{array}{l}\text { Milk, cheese \& eggs } \\
\text { (6) }\end{array}$ & $\begin{array}{l}\text { Oils \& fats } \\
\text { (7) }\end{array}$ \\
\hline SHRIDaxPost (March) & $\begin{array}{l}-0.066 \\
(0.259)\end{array}$ & $\begin{array}{l}0.921 * * \\
(0.439)\end{array}$ & $\begin{array}{l}1.233 * \\
(0.637)\end{array}$ & $\begin{array}{l}3.363 * \\
(1.698)\end{array}$ & $\begin{array}{l}0.091 \\
(1.071)\end{array}$ & $\begin{array}{l}0.104 \\
(0.346)\end{array}$ & $\begin{array}{l}0.089 \\
(0.662)\end{array}$ \\
\hline SHRID ${ }^{\mathrm{a}} \mathrm{x}$ Post (April) & $\begin{array}{l}0.444 \\
(0.333)\end{array}$ & $\begin{array}{l}1.973 * * \\
(0.936)\end{array}$ & $\begin{array}{l}2.491 * \\
(1.426)\end{array}$ & $\begin{array}{l}4.484 * * \\
(2.151)\end{array}$ & $\begin{array}{l}2.886 \\
(2.481)\end{array}$ & $\begin{array}{l}0.583 * \\
(0.314)\end{array}$ & $\begin{array}{l}0.375 \\
(1.140)\end{array}$ \\
\hline SHRID ${ }^{a} x$ Post (May) & $\begin{array}{l}0.090 \\
(0.474)\end{array}$ & $\begin{array}{l}2.226^{*} \\
(1.107)\end{array}$ & $\begin{array}{l}3.437 * \\
(1.748)\end{array}$ & $\begin{array}{l}4.528 \\
(3.054)\end{array}$ & $\begin{array}{l}-1.865 \\
(4.302)\end{array}$ & $\begin{array}{l}1.026^{* *} \\
(0.482)\end{array}$ & $\begin{array}{l}1.292 \\
(0.940)\end{array}$ \\
\hline Post (February) ${ }^{\mathrm{b}}$ & $\begin{array}{l}0.389 \text { *** } \\
(0.119)\end{array}$ & $\begin{array}{l}0.780 * * * \\
(0.185)\end{array}$ & $\begin{array}{l}0.013 \\
(0.335)\end{array}$ & $\begin{array}{l}2.646 * * * \\
(0.482)\end{array}$ & $\begin{array}{l}1.655^{* * *} \\
(0.576)\end{array}$ & $\begin{array}{l}0.593 * * * \\
(0.209)\end{array}$ & $\begin{array}{l}0.310 \\
(0.399)\end{array}$ \\
\hline Post (March) ${ }^{\mathrm{b}}$ & $\begin{array}{l}0.833 * * * \\
(0.272)\end{array}$ & $\begin{array}{l}1.144 * * \\
(0.536)\end{array}$ & $\begin{array}{l}-0.115 \\
(0.747)\end{array}$ & $\begin{array}{l}-0.287 \\
(1.018)\end{array}$ & $\begin{array}{l}0.658 \\
(1.208)\end{array}$ & $\begin{array}{l}0.599 \\
(0.363)\end{array}$ & $\begin{array}{l}1.387 \\
(0.912)\end{array}$ \\
\hline Post (April) ${ }^{\mathrm{b}}$ & $\begin{array}{l}1.278 * * * \\
(0.263)\end{array}$ & $\begin{array}{l}1.230 * * \\
(0.566)\end{array}$ & $\begin{array}{l}-0.416 \\
(0.893)\end{array}$ & $\begin{array}{l}4.167 * * * \\
(1.383)\end{array}$ & $\begin{array}{l}3.055 \\
(1.803)\end{array}$ & $\begin{array}{l}0.631 * \\
(0.346)\end{array}$ & $\begin{array}{l}1.142 \\
(1.075)\end{array}$ \\
\hline Post (May) ${ }^{b}$ & $\begin{array}{l}1.687 * * * \\
(0.409)\end{array}$ & $\begin{array}{l}0.959 \\
(0.740)\end{array}$ & $\begin{array}{l}-0.709 \\
(1.110)\end{array}$ & $\begin{array}{l}0.610 \\
(1.729)\end{array}$ & $\begin{array}{l}13.700 * * * \\
(3.537)\end{array}$ & $\begin{array}{l}0.603 * \\
(0.326)\end{array}$ & $\begin{array}{l}0.533 \\
(0.860)\end{array}$ \\
\hline Control variables & $\mathrm{Y}$ & $\mathrm{Y}$ & $\mathrm{Y}$ & Y & Y & $\mathrm{Y}$ & $\mathrm{Y}$ \\
\hline Outlier value excluded ${ }^{c}$ & $\mathrm{~N}$ & $\mathrm{~N}$ & $\mathrm{~N}$ & $\mathrm{Y}$ & $\mathrm{N}$ & $\mathrm{N}$ & $\mathrm{N}$ \\
\hline R-squared & 0.550 & 0.323 & 0.146 & 0.363 & 0.549 & 0.317 & 0.171 \\
\hline Number of observations & 154 & 154 & 154 & 149 & 154 & 153 & 154 \\
\hline Number of groups & 31 & 31 & 31 & 30 & 31 & 31 & 31 \\
\hline
\end{tabular}

The dependent variable is the HICP (base $=2015$ ) for all food items. Robust standard errors in the parenthesis

${ }^{\text {a }}$ SHRID stands for Stay-at-Home Restriction Index Dummy. SHRID $=1$ if SHRI $>1.19$ and SHRID $=0$ if SHRI $\leq 1.19$

${ }^{\mathrm{b}}$ Base month = January 2020

${ }^{\mathrm{c}}$ Cyprus is excluded from the sample due to the presence of an outlier value

$* * * p<0.01, * * p<0.05, * p<0.10$ 
estimate showed a 3.363 point increase in the HICP in the high restriction group relative to the low restriction group, the graphical analysis (SM 6) suggests that vegetable prices did not change much between February and March in the high restriction group. The large difference was driven by a fall in vegetable prices in the low restriction group in March relative to January and February.

Extending the analysis from March to April and May, the overall food prices continued to rise in the high restriction countries in April but somewhat stabilised in May. However, these results need cautious interpretation. As the low restriction countries imposed stricter stay-athome requirements in April and May, the distinction between the high and low restriction groups became blurred. Therefore, countries could no longer be clearly identified as high and low restriction groups based on this measure in April and May. Graphical analysis reveals that food prices increased in both sets of countries in April and May. Due to the lack of a clean identification strategy and a small sample size, the extent to which this variation is due to stay-at-home restrictions cannot be determined with adequate confidence.

The findings presented in this paper point to an immediate impact of stay-at-home restrictions on food prices in March; the full impact of which will evolve. Hence, this exercise should be repeated as more data becomes available. The most important limitation of this study is the small sample size. Future studies should involve a larger sample and control for both the introduction and withdrawal of movement restrictions on food prices. Given the short duration of the restrictions and the small sample size, non-linear effects could not be examined. Future studies should investigate the non-linearity of the impact using varying temporal scales. Finally, international movement restrictions, including border closures and import and export restrictions that significantly impede the cross-border movement of goods and services, is another important area for investigation.

\section{Compliance with ethical standards}

Conflict of interest The author declares no conflict of interest.

Statements of Human Rights \& Informed Consent Not applicable.

\section{References}

Bhattacharjee, A., \& Jahanshah, A. (2020). The COVID-19 crisis brings spring season for translucent activity. Does it result exogenous uncertainty for the entrepreneurs and bound-less commodity pricing! SSRN. https://doi.org/10.2139/ssrn.3568972.

Cappelli, A., \& Cini, E. (2020). Will the COVID-19 pandemic make us reconsider the relevance of short food supply chains and local productions? Trends in Food Science \& Technology, 99, 566-567.

Cullen, M. (2020). COVID-19 and the risk to food supply chains: How to respond? Food and Agricultural Organization Technical Paper. http://www.fao.org/3/ca8388en/CA8388EN.pdf.

Deutsche Welle. (2020). Coronavirus: What are the lockdown measures across Europe? https://www.dw.com/en/coronavirus-what-are-thelockdown-measures-across-europe/a-52905137.

ECDC (European Centre for Disease Prevention and Control). (2020). Download today's data on the geographic distribution of COVID-19 cases worldwide. https://www.ecdc.europa.eu/en/publications-data/ download-todays-data-geographic-distribution-covid-19-casesworldwide.

European Commission. (2020a). Temporary reintroduction of border control. https://ec.europa.eu/home-affairs/what-we-do/policies/ borders-and-visas/schengen/reintroduction-border-control_en.

European Commission. (2020b). Enhancement of EU-Turkey bilateral trade relations and modernisation of the EU-Turkey Customs Union. https://ec.europa.eu/trade/policy/countries-and-regions/ countries/turkey/.

Eurostat. (2020). Harmonised Index of Consumer Prices (HICP). https:// ec.europa.eu/eurostat/data/database.

Hale, T., Webster, S., Petherick, A., Phillips, T., \& Kira, B. (2020a). Oxford COVID-19 government response tracker. Blavatnik School of Government. Retrieved from: www.bsg.ox.ac.uk/ covidtracker.

Hale, T., Petherick, A., Phillips, T., \& Webster, S. (2020b). Variation in government responses to COVID-19. Version 6.0. Blavatnik School of Government Working Paper. May 25, 2020. Retrieved from: www.bsg.ox.ac.uk/covidtracker.

Power, M., Doherty, B., Pybus, K., \& Pickett, K. (2020). How Covid-19 has exposed inequalities in the UK food system: The case of UK food and poverty. Emerald Open Research, 2(11), 11.

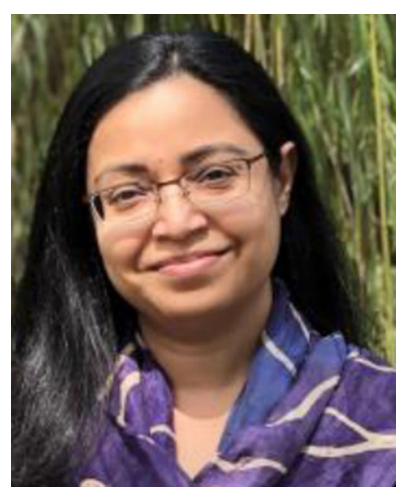

Dr. Sonia Akter is Assistant Professor at the Lee Kuan Yew (LKY) School of Public Policy at the National University of Singapore. Before joining the LKY School, she was Scientist at the International Rice Research Institute (IRRI) where she led the Gender Research Team and was the coordinator for gender research of the Global Rice Science Partnership (GRiSP) program of the CGIAR. From 2011 to 2013, she was Senior Researcher at the Helmholtz Centre for Environmental Research-UFZ, Leipzig, Germany. She completed her $\mathrm{PhD}$ in Environmental Management and Development from the Crawford School of Public Policy at the Australian National University, Australia. 